\title{
Chlorine Decay Simulation in Water Distribution System Using EPANET
}

\author{
Nur Shazwani Muhammad ${ }^{*}$, Siew Ming Shin ${ }^{1}$, Jazuri Abdullah ${ }^{2}$ \\ ${ }^{1}$ Department of Civil Engineering, Faculty of Engineering and Built Environment, \\ Universiti Kebangsaan Malaysia, 43600 Bangi, Selangor, MALAYSIA \\ ${ }^{2}$ Faculty of Civil Engineering, \\ Universiti Teknologi MARA, 40450 Shah Alam, Selangor, MALAYSIA \\ *Corresponding Author
}

DOI: https://doi.org/10.30880/ijie.2021.13.03.011

Received 20 December 2020; Accepted 01 May 2021; Available online 06 June 2021

\begin{abstract}
Chlorine is used as a disinfectant in the water treatment process so that treated water is delivered safely to consumers. However, chlorine concentration decays when water flows from the treatment plant to the supply point, due to the reaction with natural organic matter and the inner surface of the pipe. Low chlorine concentration may encourage bacteria re-growth, while high chlorine concentration can result in the formation of harmful chemical components. Therefore, this study aims to simulate the complex process of chlorine decay using EPANET. This exercise enables the determination the chlorine concentration dosage required to maintain the desired requirement given by the World Health Organization (WHO) and the Ministry of Health, Malaysia (MOH). A successful model with an extended period of simulations of 72 hours enable the mapping of spatial and temporal variations of flow and residue chlorine concentrations at all links and nodes. Constant chlorine dosage of $3.96 \mathrm{mg} / \mathrm{l}$ at node R1 has successfully satisfy the requirement given by WHO and MOH. The residue chlorine concentrations at the nodes and links in the water distribution system also depends on the water usage at node 5, the size of service reservoir and service tank and distance from the reservoir.
\end{abstract}

Keywords: Chlorine decay, chlorine decay simulation, water distribution system, hydraulic modelling, EPANET

\section{Introduction}

Malaysia is blessed with abundance of water resources, owing to its high annual precipitation, that is between $1,800 \mathrm{~mm}$ to $3,000 \mathrm{~mm}$ [1], [2]. However, surface water is prone to pollution [3]. Thus, this water resource needs to be treated before it is supplied to the public. In water treatment plants, chlorine is commonly used as a disinfectant to ensure that the water is free from pollutant. The sources of pollutant are surface runoff from the squatters' settlement, wet markets, quarry and agriculture activities [3]. Chlorine is chosen because it is easy to use, highly successful in eliminating water-borne contaminants the dosage can be easily controlled, and cost effective. Chlorine destroys waterborne contaminants by penetrating mucus coatings and cell walls, kills germs or causes them to be unable to reproduce and reduce unpleasant odours in surface water. Chlorine, chloramines, or chlorine dioxide are the common types of chlorine compounds used for water treatment [4].

The disadvantage of using chlorine as a disinfectant in the water distribution system is that its concentration decreases as water flows through the distribution system, due to chemical reactions between chlorine and natural organic matter (known as bulk decay, $\mathrm{k}_{\mathrm{b}}$ ) and with the inner surface material of pipes (known as wall decay, $\mathrm{k}_{\mathrm{w}}$ ) [4]. 
Thus, it is challenging to ensure that the chlorine concentration maintains at a minimum range between 0.3 and 0.5 $\mathrm{mg} / \mathrm{l}$, following the requirements by the World Health Organisation (WHO) and the Ministry of Health, Malaysia $(\mathrm{MOH})$. Reactions in bulk water have been characterized separately from chlorine reactions with pipe walls and biofilms or chemical deposit matrices attached to pipe walls (wall decay) [5]. This is because these two decay processes show different chlorine decay dynamics and it is difficult to restore the resulting decay parts in the distribution system corresponding to both processes. There are several models based on more complex materials reaction than the simple first order-based reaction models. Fisher et al. [6] attempt to take into account the deviation from the first order reaction to the rate of chlorine decay when the entire decay curve is taken into account.

This study aims to simulate the complex process of chlorine decay using EPANET software. This exercise enables the determination of the magnitude and location of critical residue chlorine concentration in the water distribution system, and the rate of chlorine concentration required to maintain the desired minimum requirement given by the $\mathrm{WHO}$ and $\mathrm{MOH}$.

\section{Study Area}

The study was conducted at an industrial area in a southern state in Peninsular Malaysia. The water distribution system consists of a $24.9 \mathrm{~km}$ long pipe and four tanks, i.e. one balancing reservoir, two service reservoirs and one service tanks before reaching supply point.

\section{Hydraulic and Residue Chlorine Simulations Using EPANET Software}

EPANET is a public domain software that is widely used to analyse the hydraulic characteristics and water quality conditions of a water supply distribution network [5]. This software has been utilised by several researchers since the 1990s [7-9] to estimate the amount of chlorine that remains in the water distribution system after chlorination. The EPANET software is developed based on the basic principles of energy conservation and continuity equations, where continuity equations show that the algebraic sum of the flow rate in a pipe meeting at a node along with any external flow is zero. Detailed discussion on the hydraulic and residue chlorine modelling is given in the following sub-sections.

\subsection{Data Requirements}

The first step in hydraulic modelling is establishing the dimensions (in $\mathrm{m})$, flow units $\left(\mathrm{m}^{3} / \mathrm{hr}\right.$ ) and headloss formula (Hazen-Williams equation). Following this, a representation of the water supply distribution network in the EPANET software is drawn (as shown in Fig. 1) based on a schematic diagram provided by the water supply company. In this water distribution system diagram, the four tanks, i.e. one balancing reservoir, two service reservoirs and one service tanks and supply point are treated as nodes, while pipes and pump are known as links. Hydraulic input parameters required in EPANET include pipe diameter (in $\mathrm{mm}$ ), pipe length (in $\mathrm{m}$ ), pipe roughness, ground elevation (in $\mathrm{m}$ ) and initial tank level (in m). The water distribution system includes mild steel pipe (MS) with a diameter of $650 \mathrm{~mm}$ and a length of $2.3 \mathrm{~km}$, ductile iron (DI) diameter of $900 \mathrm{~mm}$ and $0.87 \mathrm{~km}$ long, mild steel pipe of diameter $700 \mathrm{~mm}$ with a length of $9.23 \mathrm{~km}$ and soft steel pipe $900 \mathrm{~mm}$ in diameter along $12.5 \mathrm{~km}$.

The description on how the water distribution system operates is given by editing the non-visual objects, namely pump curve, base demand and daily demand pattern. For residual chlorine modelling, bulk decay is determined based on the procedure adopted by Hallam et al. [5] and then calculated according to the kinetics of the first order reaction.

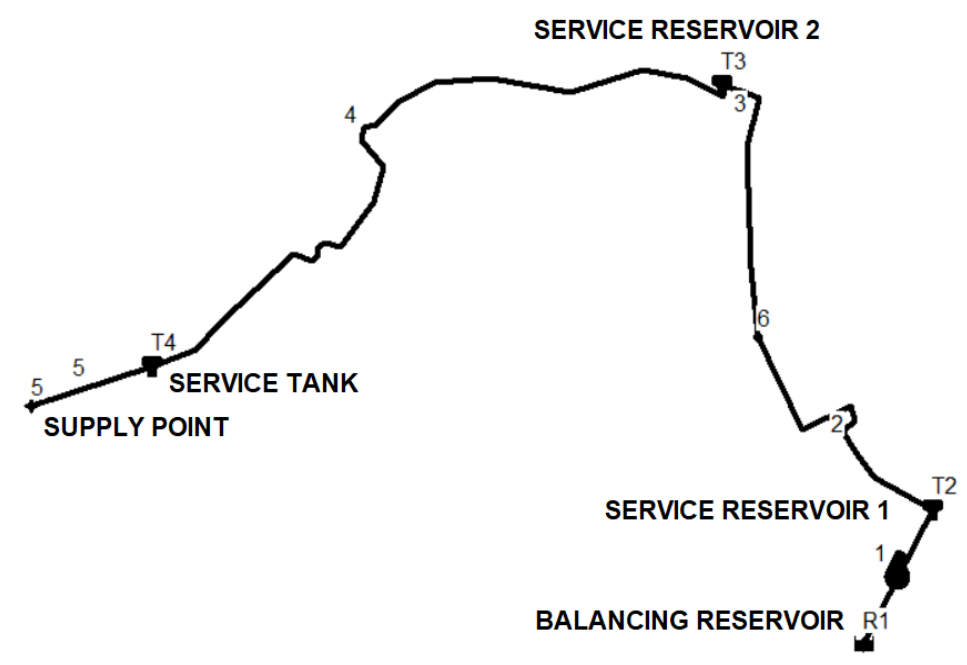

Fig. 1 - Water distribution system representation in EPANET 


\subsection{Simulations of Hydraulic and Residual Chlorine}

An extended period of analysis, i.e. 72 hours ( 3 days) was carried out to ensure that the input model is able to replicate the actual conditions of the water distribution system, including the unsteady state conditions, resulting from the variability of the demand pattern. For the purpose of model calibration, the simulated flow estimated by EPANET is compared with observed (measured) flow. A comprehensive colour-coded indicator developed by Abd Rahman et al. [10] was used to determine the model performance in replicating the real hydraulic characteristics and residual chlorine concentrations in the water distribution system.

Dirichlet boundary conditions were assigned to represent the source concentration of chlorine at the balancing reservoir to the water distribution system. Following this, the first order chlorine decay model was selected in terms of the reaction of chlorine with natural organic matter, represented by bulk decay $(\mathrm{kb})$ and the inner surface of the pipe, also known as wall decay $(\mathrm{kw})$. The wall decay coefficient $(\mathrm{kw})$ is determined by trial and error method during the model calibration process [10]. The calibration file was created based on the measurement of chlorine concentration at three points in the water distribution system.

\section{Results and Discussion}

\subsection{Hydraulic Simulation Results - Calibration and Validation}

In hydraulic simulation exercise, the evaluation of the efficiency and accuracy of a calibrated model is important to evaluate the performance of the simulated model in representing the actual behavior of the water distribution system [11]. For example, flow simulations at several nodes of the study site were conducted over a period of three days to make a comparison of the hydraulic conditions between the simulation results and observed data. Fig. 2 shows the sample of calibration result at one of the nodes in the study area. It should be noted that the calibrated parameters could replicate the high and low flow at the exact time as observed.

Other than graphical approach (as illustrated in Fig. 2), four statistical analyses were also used to evaluate the model performance, namely, the Nash-Sutcliffe Efficiency Coefficient (NSEC), Mean Absolute Error (MAE), Determination Coefficient (R2) and Discrepancies Ratio (DR) [10]. NSEC value of 1 indicates that the model is able to estimate the flow as good as the observed data, while the efficiency value of less than zero shows that the simulated result is less than the actual mean [12-13]. The value R2 approaching the value of 1 indicates that the model is more in line with the observed data. The classification of performance indicators for R2 is similar to NSEC, as the characteristics of these two indicators are similar. The value of DR equal to zero shows an accurate forecast, while DR $>0$ means excessive forecast and DR $<0$ is below forecast. Therefore, to obtain higher accuracy, the error value must be as close as possible to zero.

In this study, the estimated NSEC value is 0.9821. This proves that the developed model is successful in replicating the on-site conditions and gives good representation of observed data. Additionally, the MAE, R2 and DR values for this model are 14.01, 0.99 and 1.75, respectively. These values further validate that the simulated result is are consistent with the observed data. Thus, the accuracy and performance of this model has been proven and can be used to further simulate chlorine decay in this water distribution system.

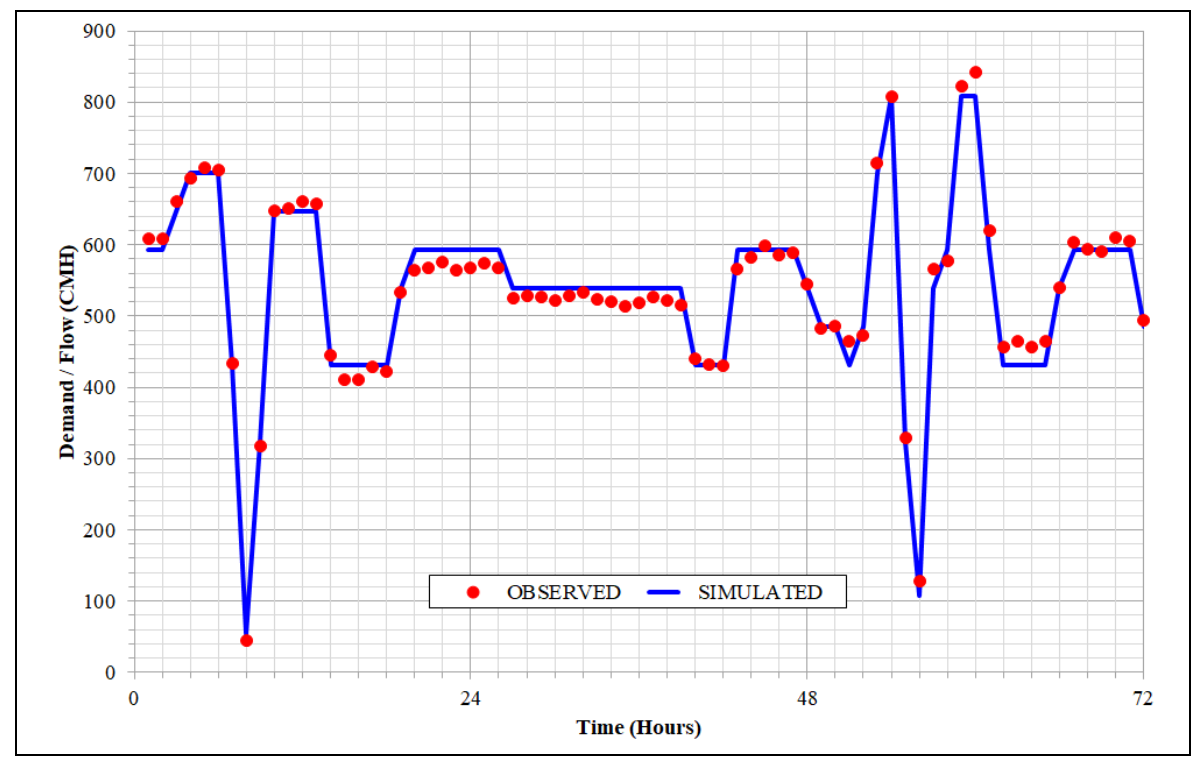

Fig. 2 - Comparison of the flow of simulation results and field test 


\subsection{Chlorine Decay Simulation Results}

The results of chlorine decay simulation presented in EPANET can be seen for every node and link, as shown in Fig. 3. The various colours represent the varying chlorine concentrations over the time series. For example, in Fig. 3(a), represents the chlorine concentration on Day 1 of simulation during an off-peak period, i.e. 2 AM. Chlorine concentrations between nodes R1 and 6 are high, that is in the range of 3.34 to $3.94 \mathrm{mg} / \mathrm{l}$. However, starting from Pipe 3 to Node 5, the chlorine concentrations are lower, specifically between 1.71 to $1.99 \mathrm{mg} / \mathrm{l}$.

Fig. 3(b) shows the state of chlorine concentration on Day 1 of simulation during a peak period, i.e. 9 AM. It should be noted that the concentrations of chlorine between R1 and Pipe 3 (in the range of 3.30 to $3.94 \mathrm{mg} / \mathrm{l}$ ) are higher than the water distribution system from node T3 to node $5(1.32$ to $1.90 \mathrm{mg} / \mathrm{l})$.

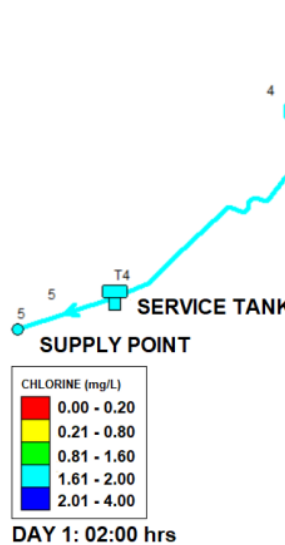

(a)

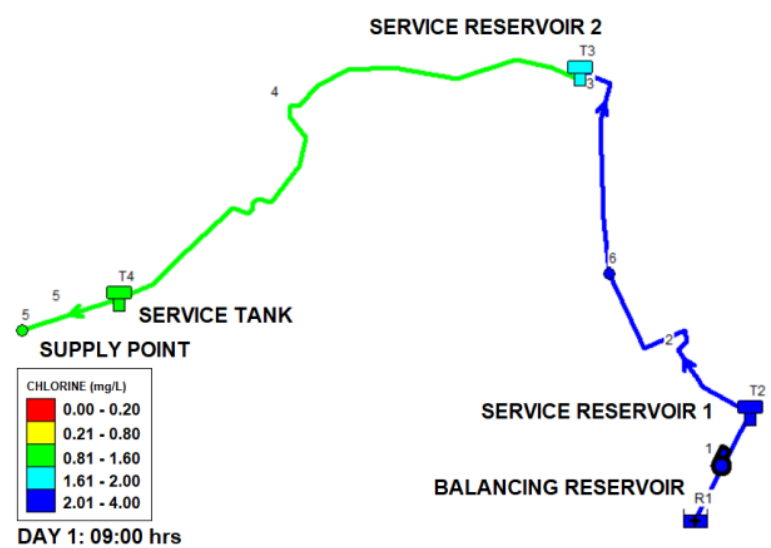

(b)

Fig. 3 - EPANET simulation results - a) off-peak period (2 AM); b) peak period (9 AM)

Fig. 4 shows the chlorine concentration time series of the nodes within the water supply distribution system. A constant chlorine concentration of $3.96 \mathrm{mg} / \mathrm{l}$ is seen in node R1. Consequently, this constant value has successfully ensured that the chlorine concentration in the water distribution system remains higher than $0.2 \mathrm{mg} / \mathrm{l}$ as required by the WHO and MOH. Interestingly, the location of node T2 which is not far from node R1, i.e. about $3 \mathrm{~km}$ and service reservoir capacity of about $3,785 \mathrm{~m}^{3}$ (1.0 million gallon) are among the factors which have resulted in consistent chlorine concentration after 10 am on Day 1 .

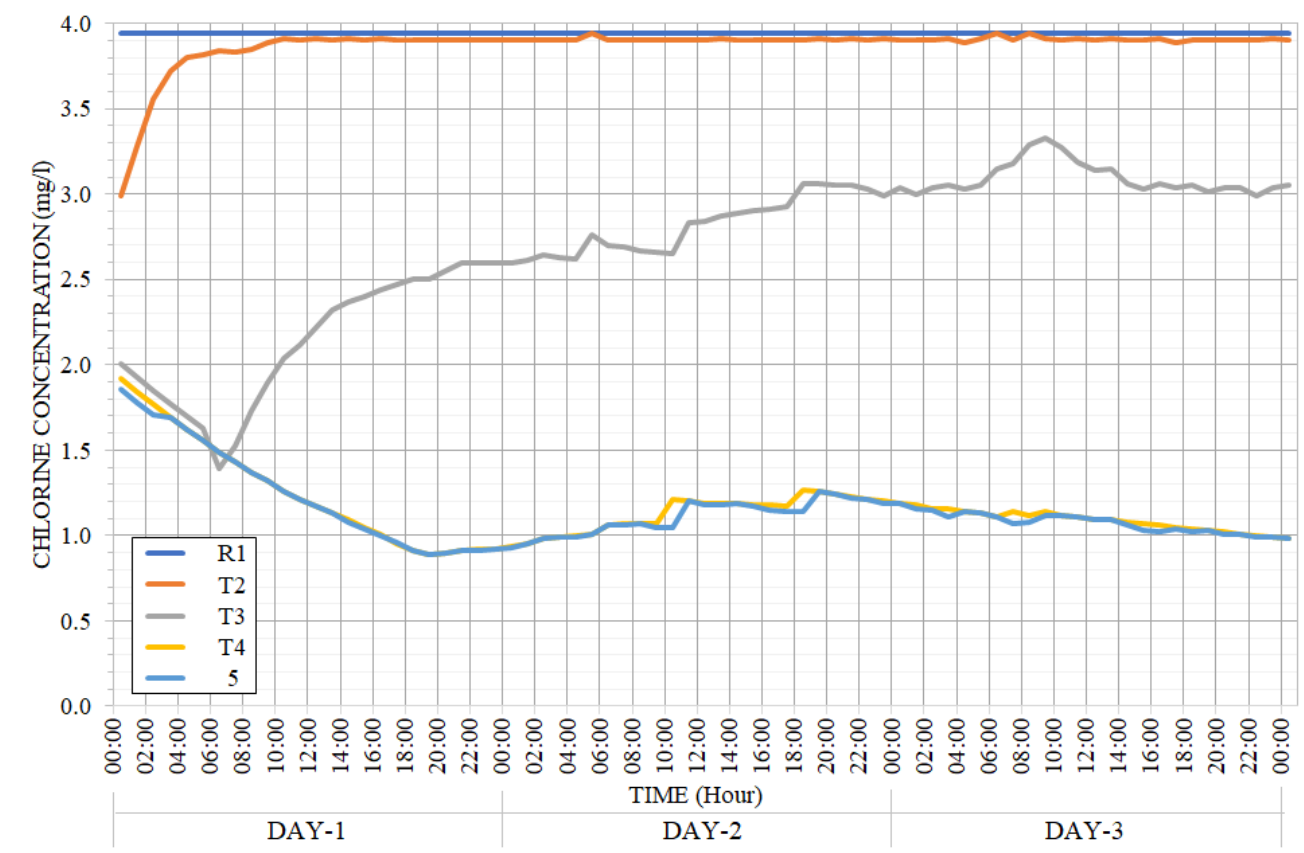

Fig. 4 - Chlorine concentration time series of the nodes in the water supply distribution system

Similar increasing trend is seen for node T3, as a result of high chlorine concentration in water supplied from node T2. On the contrary, decreasing trends in chlorine concentration are seen in nodes T4 and 5. Service tank capacity of 
node T4 is high, that is $9,463 \mathrm{~m}^{3}$, therefore the chlorine concentrations at nodes $\mathrm{T} 4$ decays as the consumption at node 5 is relatively lower than the capacity of node T4. It is also worth noting that node 5 has the same chlorine concentration as node $\mathrm{T} 4$ because of the close proximity of these nodes.

Model performance for the chlorine concentration simulation was evaluated using statistical analysis of observed data and simulated results, as shown in Table 1. The mean absolute error (MAE) error for this model is low, ranging between 0.059 and 0.939 , while the values of RMS are within a minimum of 0.080 and a maximum of 1.211 . Generally, MAE values less of than 1.5 are considered very good [10]. Additionally, the correlation between the mean (R) is 0.951 and the correlation plot for the observed values and the simulated values is shown in Fig. 6. The error values are low, therefore this confirms that the developed model is able to give results within an acceptable accuracy.

Table 1 - Model performance statistics for chlorine

\begin{tabular}{cccccc}
\hline Node & $\begin{array}{c}\text { Number of } \\
\text { observation }\end{array}$ & Observed mean & Computed mean & $\begin{array}{c}\text { Mean Absolute Error } \\
\text { (MAE) }\end{array}$ & RMS \\
\hline R1 & 3 & 3.77 & 3.94 & 0.170 & 0.208 \\
T2 & 3 & 3.57 & 3.60 & 0.059 & 0.080 \\
T3 & 3 & 2.45 & 2.55 & 0.590 & 0.734 \\
T4 & 3 & 2.29 & 1.35 & 0.939 & 1.211 \\
5 & 3 & 2.23 & 1.33 & 0.899 & 1.109 \\
\hline
\end{tabular}

Correlation between mean: $\mathbf{0 . 9 5 1}$

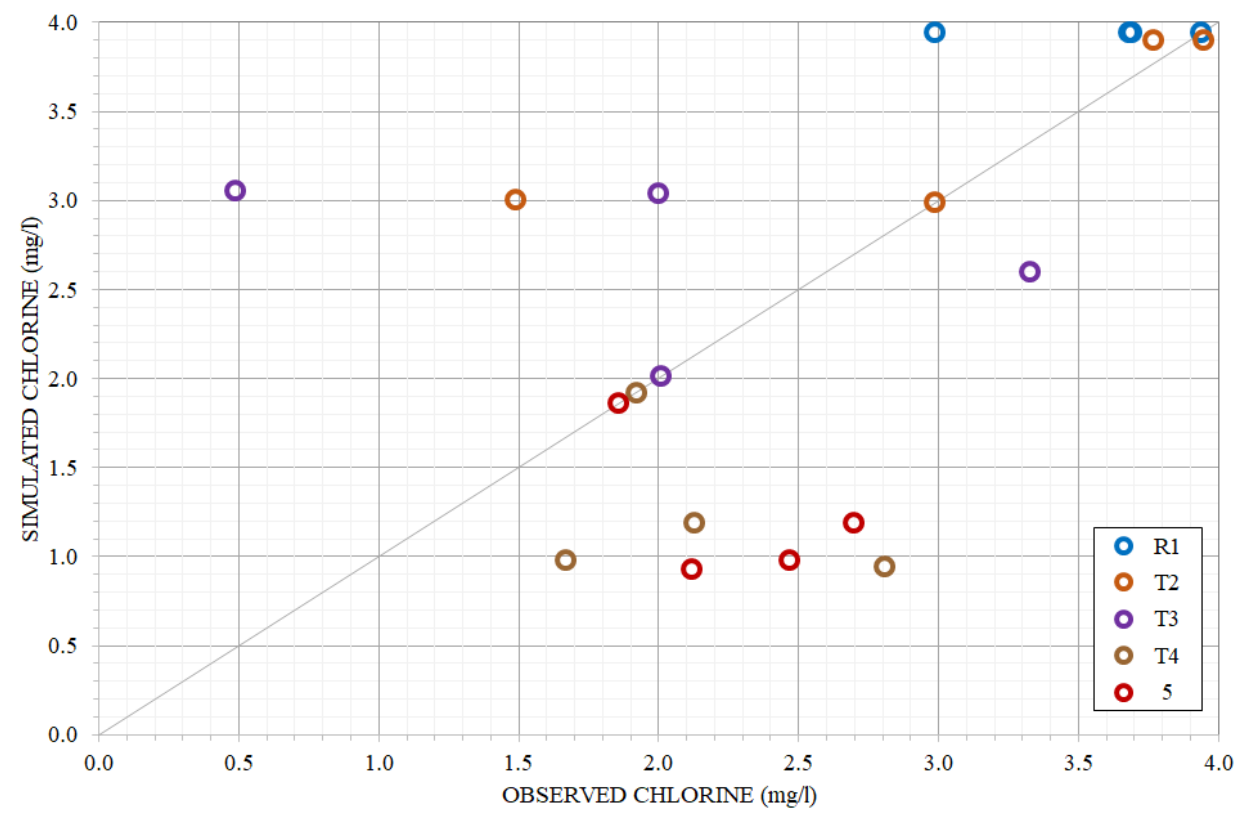

Fig. 6 - Correlation plot for chlorine

\section{Conclusion}

The complex process of chlorine decay in the water distribution system was successfully modelled using the EPANET software. The results gathered from extended period of simulations (72 hours) include the spatial and temporal variations of flow and residue chlorine concentrations at all links and nodes. Additionally, constant chlorine concentration of $3.96 \mathrm{mg} / \mathrm{l}$ at node value R1 has successfully satisfied the requirements stipulated by the WHO and $\mathrm{MOH}$, that is to make sure that the chlorine concentration at all nodes and links in the water distribution system remains higher than $0.2 \mathrm{mg} / \mathrm{l}$.

It should be noted that the residue chlorine concentrations at the nodes and links in the water distribution system also depends on the water usage at node 5, the size of service reservoir and service tank and distance from the reservoir. High water usage at node 5, along with proximity of nodes and the significant storage size of nodes T3 and T4 are among the factors that ensure continuous and reliable water supply and fulfil the requirement of residue chlorine concentrations. 


\section{Acknowledgement}

This research was funded by the Ministry of Higher Education, Malaysia, under the Fundamental Research Grant (Grant No. FRGS/1/2015/TK01/UKM/02/3). The authors appreciate the data provided by the water company.

\section{References}

[1] Muhammad N. S., Julien P. Y. \& Salas J. D. (2016). Probability structure and return period of multiday monsoon rainfall. Journal of Hydrologic Engineering, 21(1), 04015048

[2] Muhammad N. S., Abdullah J. \& Julien P. Y. (2020). Characteristics of rainfall in Peninsular Malaysia. Journal of Physics: Conference Series, 1529(5), 052014

[3] Ahmad Kamal N., Muhammad N. S. \& Abdullah J. (2020). Scenario-based pollution discharge simulations and mapping using integrated QUAL2K-GIS. Environmental Pollution, 259, 113909

[4] Ammar T. A., Abid K. Y., El-Bindar, A. A. \& El-Sonbati A. Z. (2014). Chlorine dioxide bulk decay prediction in desalinated drinking water. Desalination, 352, 45-51

[5] Hallam N. B., West J. R., Forster C. F., Powell J. C. \& Spencer I. (2002). The decay of chlorine associated with the pipe wall in water distribution systems. Water Research, 36(14), 3479-3488

[6] Fisher I., Kastl G. \& Sathasivan A. (2011). Evaluation of suitable chlorine bulk-decay models for water distribution systems. Water Research, 45(16), 4896-4908

[7] Shreedhar R. (2015). Modeling of residual chlorine for water distribution network for a pilot village. International Journal of Scientific and Engineering Research, 6(3), 469-476

[8] Biswas P. L. (1993). A model for chlorine concentration decay in pipes. Water Research, 27(12), 1715-1724

[9] Castro P. \& Neves M. (2003). Chlorine decay in water distribution systems case study - Lousada network. Environmental 2010: Situation and Perspectives for the European Union, 2(2), 1-6

[10] Abd Rahman N., Muhammad N. S., Abdullah J. \& Mohtar W. H. M. W. (2019). Model performance indicator of aging pipes in a domestic water supply distribution network. Water, 11(11), 2378

[11] Walski T. (2017). Procedure for hydraulic model calibration. Journal American Water Works Association, 109(6), 55-61

[12] Abdullah J., Muhammad N. S. \& Julien P. Y. (2019). Envelope curves for the specific discharge of extreme floods in Malaysia. Journal of Hydro-Environment Research, 25, 1-11

[13] Abdullah J., Muhammad N. S., Julien P. Y., Ariffin J. \& Shafie A. (2018). Flood flow simulations and return period calculation for the Kota Tinggi watershed, Malaysia. Journal of Flood Risk Management, 11, 5766-5782 